\title{
O PLANO DE DESENVOLVIMENTO DA EDUCAÇÃO: ANÁLISE DO PROJETO DO MEC
}

\author{
Dermeval SaViani ${ }^{*}$
}

\begin{abstract}
RESUMO: Este artigo se propõe a analisar globalmente a proposta do MEC, visando responder à seguinte pergunta: Em que medida esse novo plano se revela efetivamente capaz de enfrentar a questão da qualidade do ensino das escolas de educação básica? Para tanto, serão considerados os seguintes pontos: 1 . A configuração do PDE, procurando entender sua composição e identificar cada uma das 30 ações em que ele se desdobra; 2 . Análise da singularidade do plano em confronto com os planos anteriores, em especial com o vigente Plano Nacional de Educação; 3. A singularidade do PDE diante do problema da qualidade da educação básica; 4 . As bases de sustentação do plano, visando verificar o grau em que está apto a assegurar a qualidade da educação básica; 5. Finalmente, à guisa de conclusão, sugere-se um caminho para superar as limitaçōes do PDE.
\end{abstract}

Palavras-chave: Educação brasileira. Política educacional. Plano Nacional de Educação. Plano de Desenvolvimento da Educação.

THE EDUCATION DEVELOPMENT PLAN (EDP): ANALYSIS OF THE PROJECT OF THE MINISTRY OF EDUCATION (MEC)

ABSTRACT: This article seeks to analyze globally the proposal of the Ministry of Education (MEC) by answering the following question: to what extent is this new Plan effectively able to face the quality problem of basic education? ${ }^{* *}$ It thus explores the following elements: 1. The EDP framework, in order to understand its composition and identify each one of the 30 actions in which it is divided;

* Doutor em Educação e professor emérito da Universidade Estadual de Campinas (UNICAMP).E-mail: dermevalsaviani@yahoo.com.br

** In the current Brazilian educational system, "Basic Education" comprises all levels of education prior to higher education.

Educ. Soc., Campinas, vol. 28, n. 100 - Especial, p. 1231-1255, out. 2007 
2. An analysis of the singularity of this plan compared to the previous one, especially the current National Education Plan; 3. The singularity of the EDP when faced with the problem of the quality of basic education; 4. The foundations of the plan, by verifying to what extent it is apt to ensure the quality of basic education; 5. Finally, as a conclusion, a way to overcome the limitations of the EDP is suggested.

Key words: Brazilian education. Educational policy. National Education Plan. Education Development Plan.

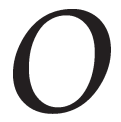

Plano de Desenvolvimento da Educação (PDE), lançado pelo MEC em 24 de abril de 2007, teve recepção favorável pela opinião pública e contou com ampla divulgação na imprensa. $\mathrm{O}$ aspecto que teria sido o principal responsável pela repercussão positiva refere-se à questão da qualidade do ensino: o PDE foi saudado como um plano que, finalmente, estaria disposto a enfrentar esse problema, focando prioritariamente os níveis de qualidade do ensino ministrado em todas as escolas de educação básica do país. Mas o "Plano" se mostra bem mais ambicioso, agregando 30 açôes que incidem sobre os mais variados aspectos da educação em seus diversos níveis e modalidades.

À aprovação quase geral contrapuseram-se algumas manifestações alertando que o Plano, tal como apresentado, não traz garantias de que as medidas propostas surtirão o efeito pretendido e esperado. Isso porque não estão claros os mecanismos de controle, permanecendo a possibilidade de que as administraçóes municipais manipulem os dados de modo a garantir o recebimento dos recursos, apresentando estatísticas que mascarem o desempenho efetivo, em detrimento, portanto, da melhoria da qualidade.

Importa, pois, empreender uma análise do PDE que vá além dessas impressões, procurando desvendar a lógica que se encontra na base tanto da formulação do Plano quanto das expectativas favoráveis que alimentam a grande aprovação que se seguiu ao seu anúncio. Para tanto, seguirei um roteiro que começa pela apreensão do objeto, buscando entender em que consiste o Plano, como ele está constituído, quais as peças que o integram e qual o significado de cada uma delas. Num segundo momento, convém compreender a singularidade desse Plano, o que implica sua comparação com os planos anteriores, em especial com o Plano Nacional de Educação que se encontra em vigor. Em 
terceiro lugar, cabe referir a singularidade do PDE à qualidade da educação básica, que é o seu objetivo precípuo. No quarto momento, são examinadas as bases de sustentação do Plano, tendo em vista verificar sua exeqüibilidade. À guisa de conclusão, alerta-se para as limitações do plano, sugerindo-se um caminho para contorná-las.

\section{O Plano de Desenvolvimento da Educação: em que consiste e como se configura}

Apresentado ao país em 15 de março de 2007, o assim chamado Plano de Desenvolvimento da Educação foi lançado oficialmente em 24 de abril, simultaneamente à promulgação do Decreto n. 6.094, dispondo sobre o "Plano de Metas Compromisso Todos pela Educação". Este é, com efeito, o carro-chefe do Plano. No entanto, a composição global do PDE agregou outras 29 ações do MEC. Na verdade, o denominado PDE aparece como um grande guarda-chuva que abriga praticamente todos os programas em desenvolvimento pelo MEC. Ao que parece, na circunstância do lançamento do Programa de Aceleração do Crescimento (PAC) pelo governo federal, cada ministério teria que indicar as ações que se enquadrariam no referido Programa. O MEC aproveitou, então, o ensejo e lançou o Índice de Desenvolvimento da Educação Básica (IDEB) e a ele atrelou as diversas ações que já se encontravam na pauta do Ministério, ajustando e atualizando algumas delas. Trata-se, com efeito, de açôes que cobrem todas as áreas de atuação do MEC, abrangendo os níveis e modalidades de ensino, além de medidas de apoio e de infra-estrutura. As 30 ações apresentadas como integrantes do PDE aparecem no site do MEC de forma individualizada, encontrando-se justapostas, sem nenhum critério de agrupamento. Contudo, de modo geral, as ações podem ser distribuídas da seguinte maneira:

No que se refere aos níveis escolares, a educação básica está contemplada com 17 ações, sendo 12 em caráter global e cinco específicas aos níveis de ensino. Entre as ações que incidem globalmente sobre a educação básica situam-se o "FUndeB", o "Plano de Metas do PDEIDEB", duas ações dirigidas à questão docente ("Piso do Magistério" e "Formação"), complementadas pelos programas de apoio "Transporte Escolar", "Luz para Todos", "Saúde nas Escolas", "Guias de tecnologias", "Censo pela Internet", "Mais educação", "Coleção Educadores" e "Inclusão Digital". 
O Fundo de Manutenção e Desenvolvimento da Educação Básica e de Valorização dos Profissionais da Educação (FUNDEB) foi aprovado em dezembro de 2006, em substituição ao Fundo de Manutenção e Desenvolvimento do Ensino Fundamental e de Valorização do Magistério (FUNDEF), cujo prazo de vigência se esgotava no final desse ano. Como se pode ver pela própria denominação, o atual Fundo amplia o raio de ação em relação ao anterior, estendendo-se para toda a educação básica. Para isso, a participação dos estados e municípios na composição do fundo foi elevada de 15 para $20 \%$, do montante de $25 \%$ da arrecadação de impostos obrigatoriamente destinados, por determinação constitucional, para a manutenção e desenvolvimento do ensino, assegurando-se a complementação da União.

O Índice de Desenvolvimento da Educação Básica (IDEB) foi criado pelo MEC a partir de estudos elaborados pelo INEP para avaliar o nível de aprendizagem dos alunos. Tomando como parâmetros o rendimento dos alunos (pontuação em exames padronizados obtida no final das $4^{\mathrm{a}}$ e $8^{\mathrm{a}}$ séries do ensino fundamental e $3^{\mathrm{a}}$ do ensino médio) nas disciplinas Língua Portuguesa e Matemática e os indicadores de fluxo (taxas de promoção, repetência e evasão escolar), construiu-se uma escala de 0 a 10 . Aplicado esse instrumento aos alunos em 2005, chegou-se ao índice médio de 3,8. À luz dessa constatação, foram estabelecidas metas progressivas de melhoria desse índice, prevendo-se atingir, em 2022, a média de 6,0, índice obtido pelos países da Organização para Cooperação e Desenvolvimento Econômico (OCDE), que ficaram entre os 20 com maior desenvolvimento educacional do mundo. $\mathrm{O}$ ano de 2022 foi definido não apenas em razão da progressividade das metas, mas à vista do caráter simbólico representado pela comemoração dos 200 anos da Independência política do Brasil.

Pelo programa "Piso do Magistério" propõe-se elevar gradativamente o salário dos professores da educação básica até atingir, em 2010, o piso de $\mathrm{R} \$ 850,00$ para uma jornada de 40 horas semanais. No que se refere à formação docente, o PDE pretende oferecer, por meio da Universidade Aberta do Brasil (UAB), cursos de formação inicial e continuada de docentes da educação básica, esperando atingir aproximadamente dois milhões de professores.

As ações de apoio ao desenvolvimento da educação básica estão representadas pelos seguintes programas: "Transporte Escolar”, que visa 
garantir aos alunos do meio rural o acesso às escolas. "Luz para Todos", por sua vez, se propõe a dotar todas as escolas rurais de energia elétrica. Com o programa "Saúde nas Escolas" pretende-se, com a colaboração do ministério da saúde e das equipes de saúde da família, assegurar atendimento básico a alunos e professores no interior das próprias escolas. A ação "Guia das Tecnologias Educacionais" busca qualificar propostas de melhoria dos métodos e práticas de ensino pelo recurso a técnicas, aparatos, ferramentas e utensílios tecnológicos. O "Educacenso" é um sistema de coleta de dados que pretende efetuar levantamento de dados pela Internet, abrangendo, de forma individualizada, cada estudante, professor, turma e escola do país, tanto das redes públicas (federal, estaduais e municipais) quanto da rede privada. $\mathrm{O}$ programa "mais educação" se propõe a ampliar o tempo de permanência dos alunos nas escolas, o que implica também a ampliação do espaço escolar para a realização de atividades educativas, artísticas, culturais, esportivas e de lazer, contando com o apoio dos ministérios da Educação, Cultura, Esporte e Desenvolvimento Social. Pela ação "Coleção Educadores" pretende-se tornar disponíveis nas escolas e bibliotecas públicas de educação básica uma coleção de sessenta volumes, reunindo autores clássicos da educação, sendo 30 de educadores brasileiros e 30 de estrangeiros. Por meio do programa "Inclusão Digital", o MEC planeja distribuir computadores às escolas de educação básica, começando pelo nível médio, que terá cobertura total em 2007, e estendendo-se a todas as escolas de nível fundamental até 2010.

Ainda no âmbito da educação básica, há ações que incidem sobre determinado nível de ensino. Assim, a ação "Proinfância" é dirigida especificamente à educação infantil, visando garantir o financiamento para a construção, ampliação e melhoria de creches e pré-escolas. No que se refere ao ensino fundamental, foram previstas três ações: uma delas é a "Provinha Brasil", destinada a avaliar o desempenho em leitura das crianças de 6 a 8 anos de idade, tendo como objetivo verificar se os alunos da rede pública estão conseguindo chegar aos 8 anos efetivamente alfabetizados; a segunda é o "Programa Dinheiro Direto nas Escolas", que concederá, a título de incentivo, um acréscimo de 50\% de recursos financeiros às escolas que cumprirem as metas do IDEB; e a terceira é o "Gosto de Ler", que pretende, por meio da Olimpíada Brasileira da Língua Portuguesa, estimular o gosto pela leitura nos alunos do ensino fundamental. $\mathrm{O}$ ensino médio foi contemplado com uma 
ação, "Biblioteca na Escola", que pretende colocar nas bibliotecas das escolas de nível médio obras literárias e universalizar a distribuição de livros didáticos, cobrindo as sete disciplinas que integram o currículo do ensino médio. Registre-se que essa ação também se propõe, no âmbito do "Programa Nacional Biblioteca da Escola", a distribuir livros de literatura para as escolas de educação infantil; e, no âmbito do "Programa Nacional do Livro Didático para a Alfabetização de Jovens e Adultos", a distribuição de livros didáticos para os alunos dos cursos de alfabetização de jovens e adultos desenvolvidos pelo "Programa Brasil Alfabetizado".

No que se refere à educação superior, o Plano inscreve cinco ações: "FIES-PROUNI", que pretende facilitar o acesso ao crédito educativo e estender o prazo de ressarcimento, além de permitir o parcelamento de débitos fiscais e previdenciários às instituições que aderirem ao PROUNI; "Pós-doutorado", destinado a reter no país pessoal qualificado em nível de doutorado, evitando a chamada "fuga de cérebros"; "Professor Equivalente", que visa facilitar a contratação de professores para as universidades federais; "Educação Superior", cuja meta é duplicar, em dez anos, o número de vagas nas universidades federais; e o "Programa Incluir: Acessibilidade na Educação Superior”, que visa ampliar o acesso de pessoas portadoras de deficiências a todos os espaços e atividades das instituições federais de ensino superior.

Além dos níveis de ensino houve, também, modalidades de ensino que foram contempladas com ações do PDE. A modalidade "Educação de Jovens e Adultos" conta com o programa "Brasil Alfabetizado". Criado em 2003, esse Programa foi reformulado no contexto do PDE, prevendo que no mínimo $70 \%$ dos alfabetizadores sejam constituídos por professores da rede pública, que trabalhariam num turno distinto daquele em que realiza sua atividade regular como docente. Para a modalidade "Educação Especial", foram dirigidas três ações: a) "salas de recursos multifuncionais", equipadas com televisão, computadores, DVDs e materiais didáticos destinados ao atendimento especializado aos alunos portadores de deficiências; b) "Olhar Brasil", um programa desenvolvido conjuntamente pelos ministérios da educação e da saúde para identificar os alunos com problemas de visão e distribuir óculos gratuitamente; c) "Programa de Acompanhamento e Monitoramento do Acesso e Permanência na Escola das Pessoas com Deficiências Beneficiárias do Benefício de Prestação Continuada da Assistência 
Social", dirigido prioritariamente à faixa etária de 0 a 18 anos. A modalidade "Educação Tecnológica e Formação Profissional" também foi contemplada com três iniciativas: a) a ação "educação profissional" se propõe a reorganizar a rede federal de escolas técnicas, integrando-as nos Institutos Federais de Educação, Ciência e Tecnologia (IFET), triplicar o número de vagas pela via da educação a distância nas escolas públicas estaduais e municipais e articular o ensino profissional com o ensino médio regular; b) a ação "novos concursos públicos" foi autorizada pelo Ministério do Planejamento, prevendo, além de um concurso para admitir 191 especialistas no Fundo Nacional de Desenvolvimento da Educação, um outro concurso destinado a preencher 2.100 vagas nas instituições federais de educação profissional e tecnológica; c) a ação "cidades-pólo" prevê a abertura de 150 escolas federais, elevando para 350 o número de unidades da rede federal de educação tecnológica, com 200 mil novas matrículas até 2010.

Finalmente, a ação "estágio", que deve ser implementada mediante aprovação de projeto de lei encaminhado ao Congresso Nacional, caracteriza o estágio como atividade educativa supervisionada e estabelece as regras de funcionamento que garantam aos estudantes do ensino superior, ensino profissional e ensino médio a preparação metódica para o trabalho.

Singularidade do PDE: um plano de educação ou um programa de metas?

Como se depreende do item anterior, aquilo que está sendo denominado de "Plano de Desenvolvimento da Educação" consiste num aglomerado de 30 ações de natureza, características e alcance distintos entre si, o que traz à baila as seguintes questôes: Por que esse conjunto de açôes recebeu o nome de plano? Até que ponto é pertinente essa denominação? Admitida a pertinência, em que sentido essas ações formam um plano?

Como acontece com a maioria das palavras, também o termo "plano" pode assumir conotações distintas, prevalecendo aquela fixada em conseqüência dos usos que vão se estabelecendo em determinados contextos. No contexto da educação brasileira, a entrada em cena da palavra "plano" remonta ao Manifesto dos Pioneiros da Educação Nova, de 1932. O "Manifesto" diagnosticou a situação educacional do país como 
sendo marcada pela falta de "unidade de plano" e ausência de "espírito de continuidade" (Manifesto, 1984, p. 407). Para fazer face a essas limitações, propôs um "Plano de reconstrução educacional" (idem, p. 417).

O movimento dos pioneiros também se fez presente nos trabalhos da Constituinte, influenciando o enunciado da alínea "a" do artigo 150 da Constituição de 1934, que estabeleceu como competência da Uniāo "fixar o plano nacional de educação, compreensivo do ensino de todos os graus e ramos, comuns e especializados; e coordenar e fiscalizar a sua execução, em todo o território do país".

A formulação da Constituição de 1934 já contém um elemento que veio a integrar a idéia de plano nacional de educação relativa ao conteúdo abrangente, estendendo-se ao ensino em todos os seus aspectos e em todo o território nacional. Essa característica está presente na Constituição atual que, no artigo 214, prevê a aprovação, em lei, de plano nacional de educação, com duração plurianual, com o objetivo de articular e desenvolver o ensino dos diferentes níveis e integrar as ações do poder público. Nos termos da atual Lei de Diretrizes e Bases da Educação Nacional (LDB), o conteúdo abrangente do plano se refere aos níveis e modalidades de ensino.

A primeira LDB, aprovada em 1961, incumbiu ao então Conselho Federal de Educação (CFE) a tarefa de elaborar o Plano de Educação referente aos fundos nacionais do ensino primário, médio e superior. Em cumprimento ao disposto na LDB, o CFE elaborou o plano de distribuição dos recursos correspondentes aos três fundos mencionados. Tratando prioritariamente do Fundo do Ensino Primário, Anísio Teixeira, relator do processo no CFE, concebeu uma fórmula engenhosa para aplicação dos recursos financeiros. Fixou-se, a partir daí, outro elemento constitutivo da idéia de plano nacional de educação: a alocação e distribuição dos recursos financeiros destinados ao ensino. Inspirado na proposta de Anísio Teixeira, foi criado, em 1996, o FUNDEF substituído, em 2006, pelo atual FUNDEB, que manteve as mesmas características de seu antecessor. Trata-se de um Fundo de natureza contábil que define o montante de recursos que os municípios, os estados e a União devem destinar à educação básica, estabelecendo as formas de sua distribuição pelos diferentes níveis e modalidades de ensino.

O Plano Nacional de Educação, atualmente em vigor, foi aprovado em 9 de janeiro de 2001, com duração prevista para dez anos. 
Incorporando os elementos fixados ao longo dos anos, sua estrutura se assenta em três momentos: 1. Diagnóstico da situação; 2. Enunciado das diretrizes a serem seguidas; 3 . Formulação dos objetivos e metas a serem atingidos progressivamente durante o período de duração do plano. Tal estrutura é aplicada aos níveis de ensino abrangendo: 1. Educação básica (educação infantil, ensino fundamental, ensino médio) e 2. Educação superior. Às modalidades de ensino envolvendo: 1. Educação de jovens e adultos; 2. Educação a distância e tecnologias educacionais; 3. Educação tecnológica e formação profissional; 4. Educação especial e 5. Educação indígena. Ao magistério da educação básica. E ao financiamento e gestão.

Pode-se notar que as 30 ações que compóem o Plano de Desenvolvimento da Educação incidem sobre os aspectos previstos no Plano Nacional de Educação já que, como se mostrou, 17 dessas ações estão referidas à educação básica; cinco se referem à educação superior; sete dizem respeito às modalidades de ensino; e uma ação (estágio) se dirige simultaneamente ao ensino médio, educação tecnológica e profissional, e educação superior. Observa-se que não há ação dirigida especificamente à modalidade de ensino "educação indígena", nem ao financiamento e gestão. No entanto, o FUNDEB, além de dizer respeito ao financiamento e gestão, contempla explicitamente a educação indígena e quilombola.

Confrontando-se a estrutura do Plano Nacional de Educação (PNE) com a do Plano de Desenvolvimento da Educação (PDE), constata-se que o segundo não constitui um plano, em sentido próprio. Ele se define, antes, como um conjunto de ações que, teoricamente, se constituiriam em estratégias para a realização dos objetivos e metas previstos no PNE. Com efeito, o PDE dá como pressupostos o diagnóstico e o enunciado das diretrizes, concentrando-se na proposta de mecanismos que visam à realização progressiva de metas educacionais. Tive, porém, que introduzir o advérbio "teoricamente" porque, de fato, o PDE não se define como uma estratégia para o cumprimento das metas do PNE. Ele não parte do diagnóstico, das diretrizes e dos objetivos e metas constitutivos do PNE, mas se compõe de ações que não se articulam organicamente com este. Tentemos ilustrar isso com alguns exemplos.

Em relação à educação infantil há apenas uma ação, a "Proinfância”, que prevê recursos federais, via FNDE, para financiar a construção, 
ampliação e melhoria das instalações escolares. Nada é mencionado sobre as 26 metas estabelecidas pelo PNE.

No que se refere ao ensino fundamental, o PDE institui a "Provinha Brasil", que não estava prevista no PNE. O programa "Dinheiro Direto nas Escolas" consiste num mecanismo de racionalização da gestão, não se relacionando diretamente com as metas, embora possa incidir sobre a eficiência e eficácia do funcionamento das escolas e, portanto, na realização das metas que se busca alcançar. Igualmente, o programa "Gosto de Ler" não diz respeito diretamente às metas do PNE, ainda que, ao efetivar a "Olimpíada Brasileira da Língua Portuguesa", se proponha a incentivar o gosto pela leitura e escrita, o que poderá auxiliar no cumprimento da meta relativa à aprendizagem da língua vernácula por parte dos alunos do ensino fundamental. Apenas a meta 17 do PNE encontra-se diretamente contemplada no PDE, por meio da ação "Transporte Escolar". As demais 29 metas fixadas pelo PNE para o ensino fundamental não são objeto de consideração por parte de PDE.

No âmbito do ensino médio, das 20 metas definidas, o PDE contempla, com o programa "Biblioteca na Escola", parcialmente, a meta 9 do PNE, que previa, ao final de 2005, que todas as escolas de nível médio deveriam estar equipadas com biblioteca. E, pelo programa "Inclusão Digital", contempla a meta 10 do PNE, que previa, para o final de 2010, a instalação, em todas as escolas de nível médio, de equipamentos de informática. Com efeito, com a ação "Inclusão Digital", o PDE espera equipar todas as escolas já neste ano de 2007.

$\mathrm{Na}$ educação superior, ao fixar para as universidades federais a meta da duplicação de vagas até 2017, o PDE fica aquém do PNE, que, na meta 1 , se propôs a atingir, até 2010 , um número total de vagas capaz de absorver $30 \%$ da faixa etária de 18 a 24 anos, o que significa a triplicação da totalidade das vagas atuais. A meta 17 do PNE foi, de algum modo, contemplada pela ação "Pós-Doutorado". As outras 33 metas relativas à educação superior que constam do PNE não foram diretamente levadas em conta pelo PDE.

Passando dos níveis para as modalidades de ensino, verifica-se situação semelhante, isto é, as ações previstas pelo PDE se relacionam com uma ou outra meta do PNE, deixando à margem a maioria delas. A conclusão que se patenteia é que o PDE foi formulado paralelamente e sem levar em conta o disposto no PNE. E, como adotou o nome de Plano, 
projeta a percepção de que se trata de um novo Plano Nacional de Educação, que estaria sendo colocado no lugar do PNE aprovado pelo Congresso Nacional em 9 de janeiro de 2001. Para isso, porém, seria necessário que fosse aprovada uma nova lei que revogasse o atual PNE, substituindo-o por um novo plano que absorvesse as características do PDE. Mas não é disso que se trata. $\mathrm{O}$ PDE é lançado num momento em que se encontra formalmente em plena vigência o PNE, ainda que, de fato, este permaneça, de modo geral, solenemente ignorado.

O PNE foi aprovado quando o segundo mandato de Fernando Henrique Cardoso entrava em sua metade final, tendo sido mutilado com nove vetos apostos pelo Presidente da República, os quais incidiram sobre seus pontos mais nevrálgicos, isto é, aqueles referentes ao financiamento, o que levou Ivan Valente a afirmar que FHC vetou o que faria do PNE um plano (Valente, 2001, p. 37). De fato, sem se assegurar os recursos necessários, como atingir as metas propostas no Plano Nacional de Educação?

Nessas circunstâncias, considerando que o PT patrocinara a elaboração da denominada "proposta de Plano Nacional de Educação da sociedade brasileira", produzida no âmbito dos Congressos Nacionais de Educação, tendo sido, também, o PT que encabeçou a apresentação do projeto de PNE da oposição na Câmara dos Deputados, em 10 de fevereiro de 1998, esperava-se que, ao chegar ao poder com a vitória de Lula nas eleições de 2002, a primeira medida a ser tomada seria a derrubada dos vetos do PNE. Mas isso não foi feito. Além disso, a lei que instituiu o PNE previa, no artigo $3^{\circ}$, que sua implantação seria avaliada periodicamente, sendo que a primeira avaliação deveria ocorrer no quarto ano de vigência, ou seja, em 2004, para o fim de se corrigir as deficiências e distorções. Em 2004 estávamos em plena vigência do primeiro mandato de Lula, mas nada foi feito para dar cumprimento a esse dispositivo legal. E agora, quando o PNE se encontra a menos de quatro anos do encerramento de seu prazo de vigência, anuncia-se o PDE formulado à margem e independentemente do PNE. É claro que a palavra "plano", no contexto do PDE, não corresponde ao significado que essa mesma palavra adquire no contexto do PNE.

Em suma, a singularidade do PDE, isto é, aquilo que o distingue de outras peças também ligadas ao termo "plano", pode ser aferida em dois sentidos, um negativo e outro positivo. Em sentido 
negativo, constata-se que, na verdade, o PDE não se configura como um Plano de Educação propriamente dito. É, antes, um programa de ação. Assim sendo, o nome "plano" evoca, aí, mais alguma coisa como o "Plano de Metas" de Juscelino Kubitschek do que a idéia dos planos educacionais como instrumentos de introdução da racionalidade na ação educativa, entendida esta como um processo global que articula a multiplicidade dos seus aspectos constitutivos num todo orgânico. Com certeza, trata-se de uma coincidência, mas não deixa de ser curioso observar que também o plano de metas de Juscelino se definiu pelo número 30 , já que a última meta, a de número 31 , a construção de Brasília, foi definida como "meta-síntese". Foram fixadas metas com prazo de cinco anos para 30 setores básicos da economia. Deve-se, pois, reconhecer que o "Programa de Metas" de Kubitschek se revestia de maior organicidade do que o PDE, pois o conjunto de metas se distribuía em seis grupos (energia, com cinco metas; transportes, sete metas; alimentação, seis; indústrias de base, onze metas; educação, uma; construção de Brasília, uma, a meta-síntese) ligados aos aspectos estratégicos do desenvolvimento nacional (Benevides, 1976, p. 210).

Em sentido positivo, a singularidade do PDE se manifesta naquilo que ele traz de novo e que, portanto, não fazia parte do PNE e também não se encontrava nos planos anteriores. Trata-se da preocupação em atacar o problema qualitativo da educação básica brasileira, o que se revela em três programas lançados no dia 24 de abril: o "Índice de Desenvolvimento da Educação Básica" (IDEB), o "Provinha Brasil" e o "Piso do Magistério". Cumpre, pois, examinar especificamente essa questão.

\section{A singularidade do PDE e a qualidade da educação básica}

Embora o MEC tenha vinculado ao PDE, como se viu, 30 ações, sua identidade própria está dada pelo IDEB, tendo como atores coadjuvantes os programas "Provinha Brasil" e "Piso do Magistério".

O que confere caráter diferenciado ao IDEB é a tentativa de agir sobre o problema da qualidade do ensino ministrado nas escolas de educação básica, buscando resolvê-lo. E isso veio ao encontro dos clamores da sociedade diante do fraco desempenho das escolas à luz dos indicadores nacionais e internacionais do rendimento dos alunos. 
Esses clamores adquiriram maior visibilidade com as manifestações daquela parcela social com mais presença na mídia, em virtude de suas ligações com a área empresarial. Tal parcela só mais recentemente vem assumindo a bandeira da educação, em contraste com os educadores que apresentam uma história de lutas bem mais longa.

Efetivamente, a luta dos educadores pela qualidade da educação pública começa na década de 1920, com a fundação da Associação Brasileira de Educação (ABE), em 1924; adquire visibilidade com o lançamento do Manifesto dos Pioneiros da Educação Nova, em 1932, e com a Campanha em Defesa da Escola Pública, na virada da década de 1950 para os anos de 1960, na fase final da tramitação do projeto de LDB; prossegue com as Conferências Brasileiras de Educação da década de 1980 e com o Fórum Nacional em Defesa da Escola Pública na Constituinte e na nova LDB; desemboca na elaboração da proposta alternativa de Plano Nacional de Educação nos Congressos Nacionais de Educação de 1996 e 1997; e se mantém com grandes dificuldades neste início do século XXI, na forma de resistência às políticas e reformas em curso e na reivindicação por melhores condições de ensino e de trabalho para os profissionais da educação.

Com a ascensão do PT ao poder federal, sua tendência majoritária realizou um movimento de aproximação com o empresariado, ocorrendo certo distanciamento de suas bases originárias. Talvez isso explique, de certo modo, por que o MEC, ao formular o PDE, o tenha feito em interlocução com a referida parcela da sociedade e não com os movimentos dos educadores.

No contexto indicado, o PDE assume plenamente, inclusive na denominação, a agenda do "Compromisso Todos pela Educação", movimento lançado em 6 de setembro de 2006 no Museu do Ipiranga, em São Paulo. Apresentando-se como uma iniciativa da sociedade civil e conclamando a participação de todos os setores sociais, esse movimento se constituiu, de fato, como um aglomerado de grupos empresariais com representantes e patrocínio de entidades como o Grupo Pão de Açúcar, Fundação Itaú-Social, Fundação Bradesco, Instituto Gerdau, Grupo Gerdau, Fundação Roberto Marinho, Fundação EducarDPaschoal, Instituto Itaú Cultural, Faça Parte-Instituto Brasil Voluntário, Instituto Ayrton Senna, Cia. Suzano, Banco ABN-Real, Banco Santander, Instituto Ethos, entre outros. Em seu lançamento, o 
"Compromisso Todos pela Educação" definiu cinco metas: 1. Todas as crianças e jovens de 4 a 17 anos deverão estar na escola; 2. Toda criança de 8 anos deverá saber ler e escrever; 3 . Todo aluno deverá aprender o que é apropriado para sua série; 4 . Todos os alunos deverão concluir o ensino fundamental e o médio; 5 . O investimento necessário na educação básica deverá estar garantido e bem gerido.

Eis como a empresária Milú Villela, presidente do Museu de Arte Moderna de São Paulo, do Instituto Itaú Cultural, do Faça Parte-Instituto Brasil Voluntário e agora também do Comitê Executivo do "Compromisso Todos Pela Educação", comentou, em artigo publicado no jornal Folha de S. Paulo (6 set. 2006, p. A-3), as cinco metas enunciadas:

A meta um estabelece que, até $2022,98 \%$ das crianças e jovens de 4 a 17 anos estarão na escola. Hoje, $97 \%$ de brasileiros entre 7 e 14 anos estão matriculados na rede pública. Entre 4 e 17 anos, são apenas $88 \%$. A meta dois projeta que toda criança de oito anos saberá ler e escrever. A meta três estima que pelo menos $60 \%$ dos alunos deverão aprender o que é apropriado para a sua série. Segundo o SAEB (Sistema Nacional de Avaliação da Educação Básica), apenas $25 \%$ dos alunos atingem esse nível em língua portuguesa, e $10 \%$ o atingem em matemática. Pela meta quatro, $80 \%$ dos jovens deverão ter completado o ensino fundamental até os 16 anos, e $70 \%$, o ensino médio até os 19 anos, o que exigirá um salto importante. A meta cinco trata do financiamento público necessário para suportar o cumprimento das quatro metas anteriores: até 2011, e mantendo pelos 11 anos seguintes, o investimento em educação básica terá de corresponder a $5 \%$ do PIB, um significativo avanço em relação aos 3,5\% de hoje. (Villela, 2006, p. A-3)

No lançamento do PDE, em 24 de abril de 2007, foi baixado pelo Presidente da República o Decreto n. 6.094, com a seguinte ementa:

Dispõe sobre a implementação do Plano de Metas Compromisso Todos pela Educação, pela União Federal, em regime de colaboração com Municípios, Distrito Federal e Estados, e a participação das famílias e da comunidade, mediante programas e açōes de assistência técnica e financeira, visando a mobilização social pela melhoria da qualidade da educação básica.

O Capítulo I do Decreto trata do "Plano de metas Compromisso Todos pela Educação", definindo a participação da "União, Estados, Distrito Federal e Municípios, atuando em regime de colaboração, das famílias e da comunidade, em proveito da melhoria da qualidade da educação básica" e estabelecendo 28 diretrizes a serem seguidas pelos 
participantes do plano. O Capítulo II dispõe sobre o Índice de Desenvolvimento da Educação Básica; o Capítulo III define os termos da adesão voluntária dos municípios, estados e Distrito Federal ao Compromisso; e o Capítulo IV estabelece as disposiçóes gerais (Seção I) e o Plano de Ações Articuladas (Seção II) como requisitos para que se dê a assistência técnica e financeira da União aos entes federativos participantes do Compromisso.

No mesmo dia 24 de abril de 2007, o MEC baixou a Portaria Normativa n. 10, instituindo a Avaliação de Alfabetização "Provinha Brasil", pela qual se procurou tornar exeqüível a meta 2 do movimento "Todos pela Educação" que se propunha a garantir a alfabetização de todas as crianças até os 8 anos de idade. Na mesma ocasião, se anunciou a apresentação de um projeto de lei cuja ementa anunciava a regulamentação do "art. 60, inciso III, alínea 'e', do Ato das Disposições Constitucionais Transitórias, para instituir o piso salarial profissional nacional para os profissionais do magistério público da educação básica". O artigo $1^{\circ}$ fixa o valor do piso em $\mathrm{R} \$ 850,00$ mensais e o artigo $2^{\circ}$ estabelece sua implantação progressiva.

A partir desses programas, o PDE se propõe a atingir o objetivo da melhoria da qualidade da educação básica. Cumpre verificar se, tal como foi desenhado, o plano possui uma estrutura capaz de garantir a consecução desse objetivo.

\section{As bases de sustentação do PDE}

Pode-se considerar que a infra-estrutura de sustentação do PDE se assenta em dois pilares, o técnico e o financeiro, em correspondência com a dupla assistência que, conforme a Constituição e a LDB, é atribuição do MEC em relação aos estados, Distrito Federal e municípios.

Do ponto de vista técnico, o PDE se apóia em dados estatísticos referentes ao funcionamento das redes escolares de educação básica e em instrumentos de avaliação construídos a partir de indicadores do aproveitamento dos alunos e expressos nas provas aplicadas regularmente sob coordenação do INEP, a partir dos quais foi elaborado o Índice de Desenvolvimento da Educação Básica (IDEB). É este índice que se constitui no recurso técnico por excelência para monitorar a implementação do PDE, definir e redefinir as metas, orientar e reorientar as ações pro- 
gramadas e avaliar os resultados, etapa por etapa, em todo o período de operação do plano, que se estenderá até o ano de 2022.

Do ponto de vista financeiro, os recursos básicos com que conta o PDE são aqueles constitutivos do FUNDEB, aos quais o MEC se propõe a adicionar, em 2007, um bilhão de reais visando a atender prioritariamente os mil municípios com os mais baixos níveis de qualidade aferidos pelo IDEB.

Essa base infra-estrutural será suficiente para assegurar o êxito do PDE na solução do problema da qualidade do ensino ministrado nas escolas de educação básica?

No que se refere ao aspecto técnico, deve-se reconhecer que o IDEB representa um avanço importante, ao combinar os dados relativos ao rendimento dos alunos com os dados da evasão e repetência e ao possibilitar aferir, por um padrão comum em âmbito nacional, os resultados da aprendizagem de cada aluno, em cada escola. É acertada, também, a iniciativa de construir um processo sistemático e continuado de assistência técnica aos municípios como apoio e condição para incentivos financeiros adicionais. Com efeito, as avaliações têm mostrado que o ensino municipal constitui um ponto de estrangulamento a atestar que foi equivocada a política dos governos anteriores de transferir para os municípios a responsabilidade principal pelo ensino fundamental.

Além da "Prova Brasil", instituída em 2005 e que serviu de base à construção do IDEB, foi lançada no âmbito do PDE a "Provinha Brasil" para verificar o desempenho em leitura de crianças de 6 a 8 anos, tendo em vista o objetivo de garantir que, aos 8 anos, todas estejam alfabetizadas. É, sem dúvida, mais um instrumento que busca interferir na qualidade da educação, neste caso incidindo sobre um momento crucial do processo de aprendizagem escolar.

De fato, a alfabetização é a porta de entrada e a pedra de toque do sistema de ensino em seu conjunto. Mas é ilusão pensar que a alfabetização é apenas um momento inicial do processo de aprendizagem, acreditando-se que ela se completa ao final do primeiro ou do segundo ano do ensino fundamental. Nessa fase inicial, as crianças podem chegar a dominar os mecanismos da linguagem escrita. Mas reconhecer as estruturas formais da língua não é ainda incorporá-las. Ao final do primeiro ou do segundo ano é possível que as crianças as reconheçam. A 
incorporação, porém, vai se dar mediante o conjunto do currículo escolar, num trabalho pedagógico que se estende pelos anos subseqüentes. Isso pode ser percebido de modo claro na forma como funcionavam as escolas nos vários sistemas de ensino dos diferentes países. No primeiro ano do ensino primário, as professoras trabalhavam com os alunos dominantemente a questão da linguagem. Eventualmente, já transmitiam noções de história do Brasil, por exemplo, mas o faziam oralmente. A partir do segundo ano, as crianças eram levadas a estudar, por escrito, história do Brasil, assim como matemática, geografia e ciências físicas e naturais. Então, estavam continuando seu aprendizado da leitura e da escrita. Elas tinham que fazer ditado, isto é, tinham que ouvir e registrar por escrito aquilo que estavam ouvindo. A relação entre a língua falada e a língua escrita se fazia por meio do ditado, que não precisava ser de português. Podia ser um ditado de história, geografia, ciências, matemática. Por meio desse processo é que as crianças iam incorporando as estruturas da cultura letrada e era por volta do quarto ano que as habilidades básicas estavam fixadas, atingindo-se o ponto de irreversibilidade, de tal modo que, mesmo que não se lesse mais nada, não se regrediria à condição de analfabeto. Em contrapartida, se o processo fosse encerrado após a conclusão, com êxito, do primeiro ou do segundo ano, sob o argumento de que o objetivo da alfabetização já tinha sido alcançado, a regressão seria inevitável; e, em pouco tempo, aquelas crianças voltariam à condição de analfabetas.

É o fenômeno descrito que explica o fracasso das campanhas de alfabetização. Por que essas campanhas fracassam? Fracassam porque elas são esporádicas, elas são descontínuas, não duram o tempo suficiente para se atingir o ponto de irreversibilidade. Em geral, os alfabetizandos, após alguns meses, chegam a redigir bilhetes simples, chegam a escrever pequenos textos e aí se comemora o feito de que em poucos meses se alfabetizou, dá-se o diploma, faz-se uma festa e depois de um ano os diplomados regridem à condição de analfabetos. Em verdade, a forma própria de se resolver esse problema é a universalização da escola elementar. Não surgiu ainda um mecanismo mais adequado.

À luz das considerações apresentadas, não parece apropriada a afirmação contida na justificativa da "Provinha Brasil", fixando como objetivo a alfabetização das crianças aos 8 anos de idade. Nesse momento, o objetivo a ser atingido é o domínio da estrutura formal da língua, a capacidade de reconhecer os códigos escritos. O processo de 
alfabetização, propriamente dito, prossegue envolvendo todo o currículo escolar, só se completando por volta da quarta ou quinta série do ensino fundamental. Mas é acertado o empenho em agir sobre aquela primeira fase, garantindo que, nos dois primeiros anos, as crianças adquiram o domínio da estrutura formal da língua pelo reconhecimento dos códigos escritos. Essa fase não pode ser alongada indefinidamente ao ser deixada à mercê de processos espontaneístas, como acreditam muitos professores sob o influxo de idéias pedagógicas que vêm sendo difundidas como muito avançadas.

No que diz respeito ao aspecto financeiro, é forçoso reconhecer que o FUNDEB representa considerável avanço em relação ao seu antecessor, o FUNDEF, ao promover a ampliação do raio de ação abrangendo toda a educação básica, não apenas no que se refere aos níveis, mas também quanto às modalidades de ensino.

Mas é preciso reconhecer também que o FUNDEB não representou aumento dos recursos financeiros. Ao contrário. Conforme foi divulgado no dia 20 de junho de 2007, na ocasião da sanção da lei que regulamentou o FUNDEB, o número de estudantes atendidos pelo Fundo passa de 30 milhões para 47 milhões, portanto, um aumento de 56,6\%. Em contrapartida o montante do fundo passou de 35,2 bilhôes para 48 bilhôes, o que significa um acréscimo de apenas 36,3\%. Esse fundo passa a abarcar toda a educação básica, sem que, em sua composição, entrem todos os recursos que estados e municípios devem destinar, por imperativo constitucional, à educação. $\mathrm{O}$ que estados e municípios farão com os $5 \%$ que lhes restam dos recursos educacionais? Se, em razão da criação do FUNDEB, esses entes federativos se sentirem estimulados a investir em outros setores para além de suas responsabilidades prioritárias (educação infantil e ensino fundamental para os municípios e ensino fundamental e ensino médio para os estados), esses recursos, com certeza, farão falta para a manutenção da educação básica. Também a complementação da União não implicou acréscimo. Com efeito, antes a União deveria entrar com pelo menos $30 \%$ de seu orçamento. Ora, o orçamento do MEC para 2007, após o corte de 610 milhôes imposto pela Fazenda, é de 9 bilhões e 130 milhões. Logo, 30\% corresponderiam a 2 bilhões e 739 milhões. No entanto, a importância prevista como complementação da União para 2007 se limita a 2 bilhões.

Em suma, o FUNDEB é um fundo de natureza contábil que não chega a resolver o problema do financiamento da educação. Representa 
um ganho de gestão; porém, não um ganho financeiro. $\mathrm{Na}$ verdade, os recursos nele alocados, se efetivamente aplicados e corretamente geridos, podem melhorar o financiamento da educação comparativamente à situação atual, mas não terão força para alterar o status quo vigente. Ou seja: uma boa gestão do fundo permitirá atender a um número maior de alunos, porém em condiçôes não muito menos precárias do que as atuais, isto é, com professores em regime de hora-aula; com classes numerosas; e sendo obrigados a ministrar grande número de aulas semanais para compensar os baixos salários que ainda vigoram nos estados e municípios.

Contudo, para ter êxito, o PDE não depende apenas da base infraestrutural. Para ser posto em operação ele vai depender, fundamentalmente, dos recursos humanos, entre os quais avulta a questão dos professores. Pode-se, pois, considerar que o terceiro pilar de sustentação do PDE é o magistério. Quanto a esse aspecto, é consenso o reconhecimento de que há dois requisitos fundamentais que devem ser preenchidos: as condições de trabalho e de salário e a formação.

O pDE cuidou da questão salarial por meio do programa "Piso do Magistério". O valor de R\$ 850,00 foi obtido tomando-se o salário de R\$ 300,00 proposto em 1994, corrigido pela inflação. Observe-se, porém, que $\mathrm{R} \$ 300,00$ correspondiam, naquele ano, a 4,28 salários mínimos, cujo valor era $\mathrm{R} \$ 70,00$. Em relação ao salário mínimo atual de $\mathrm{R} \$ 380,00$, o piso de $\mathrm{R} \$ 850,00$ corresponde a apenas 2,23 vezes. Além disso, prevê-se sua implantação gradativa pelo incremento, em 2008, de um terço do salário atual, dois terços em 2009 e apenas em 2010 chegaremos ao valor de $\mathrm{R} \$ 850,00$. Pode-se argumentar que o piso proposto, embora muito modesto, significa importante aumento para as regiões em que os salários se encontram muito depreciados. Mas é preciso também ter presente que esses salários depreciados se referem, em geral, a jornadas de 20 horas semanais, enquanto que o projeto do novo piso supõe uma jornada de 40 horas, com a indicação expressa de que o montante de $\mathrm{R} \$ 850,00$ "compreende todas as vantagens pecuniárias pagas a qualquer título". Isso tudo com o agravante de que, diferentemente da maioria das outras medidas do PDE que foram instituídas por decreto ou medida provisória, nesse caso trata-se de um projeto de lei que não se sabe se e quando será aprovado pelo Congresso Nacional. Resulta inegável, portanto, a insuficiência do que está sendo proposto, mesmo porque está aquém do que fora acordado há 13 anos. 
No que se refere às condições de trabalho, a questão principal, que o PDE não contempla, diz respeito à carreira profissional dos professores. Essa carreira teria que estabelecer a jornada integral em um único estabelecimento de ensino, de modo que se pudessem fixar os professores nas escolas, tendo presença diária e se identificando com elas. E a jornada integral, de 40 horas semanais, teria que ser distribuída de maneira que se destinassem $50 \%$ para as aulas, deixando-se o tempo restante para as demais atividades. Com isso, os professores poderiam participar da gestão da escola; da elaboração do projeto político-pedagógico da escola; das reunióes de colegiado; do atendimento às demandas da comunidade e, principalmente, além da preparação das aulas e correção de trabalhos, estariam acompanhando os alunos, orientando-os em seus estudos e realizando atividades de reforço para aqueles que necessitassem.

Para fazer face ao problema da formação docente, o PDE criou o programa "Formação" que, por meio da Universidade Aberta do Brasil (UAB), pretende oferecer cursos a distância para prover a formação inicial dos docentes em exercício não-graduados em nível superior, além de formar novos professores e possibilitar a qualificação contínua de quase dois milhões de professores da educação básica. $\mathrm{O}$ ensino a distância, nas condições atuais do avanço tecnológico, é um importante auxiliar do processo educativo. Pode, pois, ser utilizado com proveito no enriquecimento dos cursos de formação de professores. Tomá-lo, entretanto, como a base dos cursos de formação docente não deixa de ser problemático, pois arrisca converter-se num mecanismo de certificação antes que de qualificação efetiva. Esta exige cursos regulares, de longa duração, ministrados em instituições sólidas e organizadas preferencialmente na forma de universidades.

Vê-se que o PDE representa um importante passo no enfrentamento do problema da qualidade da educação básica. Só o fato de pautar essa questão como meta da política educativa e construir instrumentos de intervenção já se configura como um dado positivo que precisa ser reconhecido. Mas, em sua configuração atual, ainda não nos dá garantia de êxito.

Conclusão: para dar sustentabilidade ao plano

Na cerimônia de anúncio da sanção, pelo Presidente da República, da lei que regulamentou a implantação do FUNDEB, em 20 de ju- 
nho de 2007, o ministro Fernando Haddad aproveitou o ensejo para lançar sete novas ações: o "Selo e certificado para cidade que reduzir o analfabetismo"; o "PDE de cada escola"; os programas "Gestão da educação na saúde" e o "PET-Saúde; a segunda edição do concurso "Literatura para Todos", criado em 2006; a edição 2007 do "Programa de Apoio à Extensão Universitária" (PROEXT), lançado em 2003; o "Prodocência”, um programa de apoio aos cursos de licenciatura; e a abertura de novas vagas para professor e técnico nas escolas de educação tecnológica. Não deixa de ser bem-vindo esse dinamismo do MEC, multiplicando as ações com as quais se pretende mudar o perfil da educação brasileira, se bem que se deva estar atento para evitar a fragmentação e dispersão que levariam à perda do foco na questão principal: a melhoria da qualidade da educação básica.

Em meu entendimento, cabe avaliar como positiva a iniciativa do MEC de capitalizar a receptividade da opinião pública à questão da qualidade do ensino, expressa por setores influentes na mídia, como foi o caso da agenda do "Compromisso Todos pela Educação", lançada por um grupo de empresários. Inegavelmente, é preciso aproveitar esse momento favorável, em que a sensibilidade em torno da importância e prioridade da educação se espraia pela sociedade e parece exigir que se ultrapasse o consenso das proclamaçóes discursivas, e se traduza em ações efetivas.

No entanto, é preciso cautela para não cairmos na ingenuidade de acreditar, sem reservas, nas boas intenções que agora, finalmente, teriam se apoderado de nossas elites econômicas e políticas. Com efeito, se o MEC seguir na trilha proposta pelo movimento empresarial "Compromisso Todos pela Educação", os limites do PDE resultarão incontornáveis. Isso fica claro nas palavras da presidente desse movimento. Milú Villela, a maior acionista individual do Banco Itaú, campeã do voluntariado (é embaixadora da União da Boa Vontade da UNESCO) e presidente do Comitê Executivo do "Compromisso Todos Pela Educação", na conclusão do artigo já citado, afirma:

Até 2011, e mantendo pelos 11 anos seguintes, o investimento em educação básica terá de corresponder a 5\% do PIB, um significativo avanço em relação aos 3,5\% de hoje. Atingir as cinco metas nos próximos 16 anos é possível. Mas exigirá de todos os brasileiros paixão pelo tema, esforço concentrado e cooperação entre organizações da sociedade civil, empresas e governos. Chegou a hora de sermos todos pela educação. Para que, em 2022, pos- 
samos festejar o bicentenário da Independência num país de escola boa e de oportunidades iguais para todos. (Villela, 2006, p. A-3)

Não deixa de ser positivo que um grupo de empresários defenda a necessidade de ampliação dos recursos investidos na educação. Ao que consta, eles foram levados a essa posição em decorrência de desafio lançado pelo ministro da Educação, ao mostrar que o empresariado tem sido muito ágil para ir a Brasília pedir isenção fiscal, redução de impostos, perdão de dívidas, incentivos à produção, sem jamais incluir na pauta o aumento de recursos para a educação. Ao contrário, ao criticar os gastos públicos, propor o enxugamento das contas governamentais, exigir a redução do tamanho do Estado, eles estão inviabilizando qualquer possibilidade de ampliação dos investimentos públicos em educação.

Em resposta a esse desafio, foi proposto o movimento "Compromisso Todos pela Educação", que fixou, na meta de número 5, a necessidade de ampliação do percentual do PIB investido na educação básica. No entanto, esses mesmos empresários dão sinais de que continuam resistentes ao financiamento público da educação superior, área que eles gostariam de ver como domínio da iniciativa privada, afastada, portanto, da esfera financeira do poder público. E, admitida a hipótese de que parcela desse ensino seja mantida sob responsabilidade do Estado, defendem eles a eliminação da gratuidade. É preciso, pois, lembrá-los de que a formação de professores é, e deve ser cada vez mais, atribuição da educação superior. E, sem professores bem formados, as metas da educação básica não poderão ser atingidas. Portanto, sem uma forte ampliação do financiamento público ao ensino superior, a busca de melhoria da qualidade da educação básica terá dificuldades de chegar a resultados significativos.

O final do citado artigo assinado por Milú Villela também deixa transparecer a tendência dominante entre os empresários de considerar a educação como uma questão de boa vontade e de filantropia, que seria resolvida pelo voluntariado, ficando subjacentes os interesses mais específicos que alimentam o desejo de ajustar os processos formativos às demandas de mão-de-obra e aos perfis de consumidores postos pelas próprias empresas.

Como afirmei em entrevista ao Caderno Mais! da Folha de S.Paulo, de 29 de abril de 2007 (Saviani, 2007, p. 3), a lógica que embasa a proposta do "Compromisso Todos pela Educação" pode ser 
traduzida como uma espécie de "pedagogia de resultados": o governo se equipa com instrumentos de avaliação dos produtos, forçando, com isso, que o processo se ajuste às exigências postas pela demanda das empresas.

É, pois, uma lógica de mercado que se guia, nas atuais circunstâncias, pelos mecanismos das chamadas "pedagogia das competências" e "qualidade total". Esta, assim como nas empresas, visa obter a satisfação total dos clientes e interpreta que, nas escolas, aqueles que ensinam são prestadores de serviço; os que aprendem são clientes e a educação é um produto que pode ser produzido com qualidade variável.

No entanto, de fato, sob a égide da qualidade total, o verdadeiro cliente das escolas é a empresa ou a sociedade e os alunos são produtos que os estabelecimentos de ensino fornecem a seus clientes. Para que esse produto se revista de alta qualidade, lança-se mão do "método da qualidade total" que, tendo em vista a satisfação dos clientes, engaja na tarefa todos os participantes do processo, conjugando suas ações, melhorando continuamente suas formas de organização, seus procedimentos e seus produtos. É isso, sem dúvida, que o movimento dos empresários fiadores do "Compromisso Todos pela Educação" espera do Plano de Desenvolvimento da Educação lançado pelo MEC.

Permito-me, pois, sugerir ao MEC um caminho distinto: que a linha mestra do PDE seja uma medida de impacto que permita imediatamente mudar a situação das escolas e levantar o ânimo dos professores, que passariam a desenvolver suas atividades com entusiasmo e dedicação. Para viabilizar essa mudança, propus, em 1997, para o Plano Nacional de Educação, que se dobrasse imediatamente o percentual do PIB investido em educação, passando, dos atuais cerca de $4 \%$, para $8 \%$.

Essa proposta foi considerada inexeqüível; no entanto, ela apenas nos situaria entre os países que mais investem em educação, como eram os casos dos Estados Unidos (7,5\%), do Canadá $(7,6 \%)$, Noruega $(8,7 \%)$ e Suécia $(8,8 \%)$, segundo dados do próprio MEC em sua proposta de PNE, divulgada naquele ano. Deve-se frisar que os países mencionados já há muito consolidaram os respectivos sistemas de ensino e universalizaram a educação básica, erradicando o analfabetismo. E, mesmo nessa situação vantajosa, continuam investindo os mencionados percentuais de seus PIBs na educação. No nosso caso, que ainda temos que implantar o sistema, logicamente deveríamos investir muito mais. 
Talvez, o exemplo mais condizente com o caso do Brasil seja o da Coréia do Sul, que investiu $10 \%$ do PIB ao longo de 20 anos.

Se aplicarmos o índice de 8\% ao PIB de 2006 que, pela nova metodologia do IBGE, atingiu 2 trilhões e 322 bilhões de reais, teremos o montante de 185 bilhôes e 760 milhões de reais. Descontando-se aproximadamente $1 \%$ para o ensino superior, ou seja, 23 bilhões, teríamos, para a educação básica, 162 bilhões e 760 milhões de reais. Portanto, mais do que o triplo (3,39 vezes) dos 48 bilhôes previstos pelo FUNDEB para o mesmo ano de 2007.

Os valores mencionados indicam que, se dobrássemos o percentual do PIB, haveria recursos suficientes para tratar a educação com a devida seriedade e de acordo com a prioridade que é proclamada nos discursos, mas nunca efetivamente considerada. Procedendo da forma como estou propondo, nós estaríamos, de fato, provendo os recursos que permitiriam dar o salto de qualidade necessário para colocar a educação brasileira num patamar civilizado, condizente com a magnitude de seu território, de sua população e de sua economia. E estaríamos em condição de equipar adequadamente as escolas e dotá-las de professores com formação obtida em cursos de longa duração, com salários gratificantes, compatíveis com seu alto valor social. Isso permitirá transformar as escolas em ambientes estimulantes, nos quais as crianças, nelas permanecendo em jornada de tempo integral, não terão como fracassar; não terão como não aprender. Seu êxito será resultado de um trabalho pedagógico desenvolvido seriamente, próprio de profissionais bem preparados e que acreditam na relevância do papel que desempenham na sociedade, sendo remunerados à altura de sua importância social.

Recebido em junho de 2007 e aprovado em julho de 2007.

\section{Referências bibliográficas}

BENEVIDES, M.V.M. O governo Kubitschek: desenvolvimento econômico e estabilidade política. Rio de Janeiro: Paz \& Terra, 1976.

MANIFESTO dos Pioneiros da Educação Nova - 1932. Revista Brasileira de Estudos Pedagógicos, Brasília, DF, v. 65, n. 150, p. 407-425, maio/ago. 1984. 
SAVIANI, D. O ensino de resultados. Folha de S. Paulo, São Paulo, 29 abr. 2007. Caderno "Mais", p. 3.

VALENTE, I. Plano Nacional de Educação. Rio de Janeiro: DP\&A, 2001.

VILLELA, M. Todos pela educação de qualidade. Folha de S.Paulo, São Paulo, 6 set. 2006. Opinião, p. A-3. 